\title{
LOS PARTIDOS POLÍTICOS EN LA HISTORIA CONSTITUCIONAL BRASILEÑA.
}

\section{POLITICAL PARTIES IN THE BRAZILIAN CONSTITUTIONAL HISTORY.}

\author{
David Almagro Castro \\ Pontifícia Universidade Católica do Rio Grande do Sul
}

\begin{abstract}
SUMARIO: I. LOS PARTIDOS EN EL CONSTITUCIONALISMO BRASILEÑO: del Imperio a la $\mathrm{CF}$ 1.988. 1.1. Introducción. 1.2. Los partidos durante la época imperial. 1.3. La República Velha: el ostracismo constitucional de los partidos. 1.4. Los partidos politicos en la era Vargas. 1.4.1. Del Gobierno Provisional al Estado Nuevo (1930-1937). 1.4.2. El Estado Nuevo (1937-1945). 1.5. Los partidos durante el periodo democrático 1945-1964. 1.6. El "bipartidismo" de la dictadura militar 1964-1978 y la apertura democrática. II. A modo de conclusión.
\end{abstract}

Resumen: El presente artículo propone un análisis sobre las diferentes etapas, siguiendo la clásica distinción de Triepel, que recorrieron los partidos políticos en la historia constitucional brasileña hasta llegar a su consolidación jurídica en la vigente Constitución Federal de 1988. El objetivo principal que se persigue es poner de manifiesto la incidencia directa que para la consolidación del sistema democrático brasileño tuvo la continúa relativización y ostracismo a que el legislador y el conjunto de los operadores políticos condenaron a los partidos en el ordenamiento jurídico.

Abstract: The current paper analyses the different stages, following the popular distinction suggested by Triepel, that the Brazilian political parties needed to cross until their juridical consolidation under the current Federal Constitution of 1988. The main goal pursued is to show the direct impact for the consolidation of the brazilian democratic system caused by the attitude of the legislator and the others political operators, by both ignoring and diminishing the importance of political parties in his own legal system.

Palabras clave: historia constitucional, democracia, partidos políticos.

Key words: constitutional history, democracy, political parties.

\section{LOS PARTIDOS EN EL CONSTITUCIONALISMO BRASILEÑO: del Imperio a la CF 1.988.}

\subsection{Introducción.}

El origen y consolidación de los partidos políticos en Brasil presenta ciertas similitudes con la clásica construcción de Triepel acerca de las diferentes actitudes que el Derecho y el Estado mostraron a lo largo de los s. XIX y XX hacia éstos $^{1}$. El final del siglo XVII y el siglo XVIII trajeron consigo una revolución sin

1 Según Triepel, la relación del Estado y el Derecho con los partidos pasará por cuatro fases históricas diferentes: a) lucha, b) ignorancia, c) reconocimiento y legalización, y d) la posible era 
precedentes en la teoría y las formas de gobierno: el Estado constitucional y el parlamentarismo. Primeramente Inglaterra y posteriormente Francia y los futuros EEUU instauraron un modo de ejercer del poder basado en la separación funcional de poderes y el reconocimiento de unos derechos naturales. La limitación del poder sería la piedra angular del incipiente Estado constitucional liberal. La paulatina consolidación de las nuevas formas de gobierno fue introduciendo, no sin dificultades, la conveniencia de adoptar nuevas fórmulas de asociacionismo político colectivo en una sociedad que, como la liberal, iba a construirse en torno a la deificación del individuo.

En este contexto surgieron las primeras teorizaciones sobre el rol de los partidos políticos en el incipiente Estado constitucional liberal. El escenario fue la Inglaterra del siglo XVII. Bolingbroke y sobre todo Burke y su discurso a los electores de Bristol son tenidos comúnmente como los primeros ideólogos de los partidos políticos en el Mundo moderno. La difusión de las organizaciones partidarias al continente se produjo un siglo después en el Vormarz alemán y definitivamente en la Revolución de 1848. Tanto en Inglaterra como en Alemania su origen se dio directamente vinculado a la actividad parlamentaria. Solo paulatinamente, y preferentemente en Alemania, los partidos fueron adquiriendo una mayor presencia social como asociaciones de afiliados y grupos clientelares ${ }^{2}$.

El origen de los partidos en Brasil estuvo fuertemente marcado por el modelo de colonización y el tipo de Estado implantado. El periodo de dominación portuguesa, basado en la explotación de los recursos naturales y la implantación de un sistema de producción agricola esclavista, dejó una profunda marca en la mentalidad de las élites locales. La Independencia no provocó la superación de la dominación oligárquica y la apertura del proceso politico a amplias parcelas de la población. Al contrario. La gran mayoría de la población siguió estando excluida de los procesos económicos y políticos durante toda la etapa imperial y buena parte de la republicana. La reversión de esta situación solo se produjo en los estertores del periodo dictatorial cuyo fin condujo a la redemocratización y la publicación de la popularmente conocida como Constituição Cidadá, la CF 1988. Pero no adelantemos acontecimientos.

\subsection{Los partidos durante la época imperial.}

La proclamación de la Independencia en septiembre de 1822 se articuló sin la participación ni de las clases populares ni tan siquiera de las élites nacionales. La ruptura con la metrópolis portuguesa se gestó y artículo en los gabinetes palaciegos con el objetivo de mantener el poder en manos de la familia Bragança. La centralización del poder en manos del futuro Emperador, objetivo primordial de los rupturistas, requería de una organización constitucional que bajo una apariencia constitucional le otorgase amplios poderes y le permitiese mantener el control político en todo momento.

de incorporación constitucional. Cf. Manuel García Pelayo, Obras Completas Vol. II, Centro de Estudios Políticos y Constitucionales, Madrid, 2009, p. 1989.

${ }^{2}$ Cf. Dieter Grimm, "Los partidos politicos", en BENDA, Ernst et al., Manual de Derecho Constitucional, Marcial Pons, Madrid, 1996, pp. 389-444; Ramón García Cotarelo, Los partidos politicos, Sistema, Madrid, 1985, p. 19. 
La Constitución de 1824 no fue el producto final de una Asamblea Nacional Constituyente. D. Pedro I, haciendo uso de la fuerza militar de que disponía, decidió disolverla por considerarla indigna de su persona. Algunos parlamentarios fueron presos y otros deportados. En una declaración no exenta de cierta ironía el monarca afirmó que iría a otorgar una constitución doblemente liberal. Llegó a convocar inclusive elecciones a una nueva Asamblea Constituyente a finales de 1923 sin llegar a establecer fecha concreta. No fue sino una maniobra de distracción. Tan solo 4 meses más tarde otorgaria, "para la felicidad del pueblo brasileño", la primera constitución ${ }^{3}$.

La primera constitución de la historia de Brasil sería, pues, una Carta otorgada que nacería con un bajo grado de legitimidad y bien alejada del ideal democrático y representativo del siglo XIX basado en los derechos civiles y políticos del Hombre y la inviolabilidad constitucional de la separación de poderes. Su objetivo principal no era otro que mantener la estructura de poder centralista creada con ocasión de la proclamación de la Independencia.

La estructura de la Constitución de 1824 imposibilitaba la existencia de un régimen de partidos constitucionalmente libres e independientes. La falta de libertad de conciencia del art. 5 impedia la libre difusión de las ideas politicas; los art. 92 y 94 establecian un derecho de sufragio censitario vinculado a la capacidad económica o al estatus educativo, factores que en un país esclavista y con un alto grado de analfabetismo reducian el Cuerpo Electoral a un sector marginal de la población real; el artículo 95, III imponía la obligación a los representantes de profesar la religión estatal, resultado de la gran influencia del positivismo religioso en la etapa imperial. No hubo rastro alguno de una ley específica de partidos.

La legislación electoral ignoró la existencia de unos partidos reducidos a la función de expresión de corrientes de opinión. De entre ellas debe destacarse la denominada Lei Saraiva de 1881 que, entre otras cuestiones, impidió por vez primera el voto de los analfabetos, estableció el doble turno y el voto directo con aumento de la renta exigida para adquirir la condición de elector y elegible. El objetivo principal de este cuerpo legal fue fortalecer el voto en las zonas urbanas con mayor apoyo liberal y debilitar la influencia de los sectores rurales conservadores, dominadores del voto analfabeto.

Las restricciones constitucionales impuestas a la participación electoral y la libre creación y difusión de ideas políticas y la falta de regulación legal de los partidos dificultarian in extremis su formación durante el periodo imperial. La organización y división de los poderes acabó por imposibilitar cualquier tentativa de consolidar un régimen minimamente representativo en el cual cupieran partidos políticos dignos de tal nombre. Su ideólogo, Benjamin Constant, diseñó una estructura compuesta por cinco poderes: un poder regio, el poder ejecutivo, el poder representativo tradicional ejercido por una Câmara hereditaria y que acabaría transformándose en un Senado vitalicio, un poder representativo de la opinión residenciado en la Câmara dos Deputados y un poder judicial ejercido por magistrados nombrados por el Emperador. La composición del poder legislativo y judicial se correspondia con las prácticas políticas de la época. La clave de bóveda del edificio constitucional radicaba en quien asumiria la titularidad del poder

3 Cf. Marco Antonio Villa, A História das Constituições Brasileiras, 200 anos de luta contra o arbitrio, Leya, São Paulo, 2011, pp. 15-17. 
regio o Poder Moderador. Su concepción teórica era la de un poder neutro orientado al mantenimiento de la armonía entre los demás poderes y sin asumir cualquier prerrogativa de aquéllos. Los titulares del poder regio o Poder Moderador deberian ser distintos. El Rey no debía asumir función ejecutiva alguna ${ }^{4}$.

La construcción teórica no se correspondió con el diseño constitucional. La doctrina original de la división de poderes se vio sustituida por un modelo en el cual el Emperador sería el elemento central y determinante del mismo. A éste le correspondería el ejercicio directo del poder ejecutivo, el nombramiento de senadores y jueces y la prerrogativa de disolución de la Câmara dos Deputados, único órgano cuya composición era ajena a su voluntad. El resultado directo era acorde al objetivo principal de impedir la descentralización del poder y la indeseable participación de las élites nacionales ${ }^{5}$.

En este contexto, las incipientes asociaciones políticas sirvieron más bien para revestir de constitucionalismo el Imperio recién creado y ejercer un cierto contrapeso al marcado espíritu absolutista del Emperador. Su poder político era bien escaso, hecho que se comprobó con la disolución unilateral de la Asamblea Constituyente por el Emperador y el ostracismo a que fueron condenados algunos parlamentarios. Puede afirmarse, sin temor a equívocos, que los partidos eran poco más que un barniz constitucional en un Imperio en el que el ejercicio del poder político correspondia al Emperador y a un Consejo de Ministros nombrado por el propio monarca ${ }^{6}$.

Con la llegada al trono de D. Pedro II los partidos politicos comienzan su tortuosa andadura en la historia constitucional brasileña. La abdicación de D. Pedro I en su hijo primogénito abriría un periodo de Regencia que posibilitó la entrada en el escenario político de las élites brasileñas. La primera medida sería reformar la estructura de poder creada para permitir el acceso de las diversas oligarquías nacionales estructuradas en grupos locales. Se iniciaba la disputa entre facciones para determinar el contenido del Ato Adicional que modificaría y adecuaría la Constitución de 1824 al nuevo equilibrio de fuerzas.

Los dos principales grupos ideológicos eran los liberales - radicales y moderados - y los conservadores. La facción radical de los liberales, conocidos como farroupilhas, pretendía descentralizar profundamente el poder. Para ello deberian derogar las instituciones características del reinado de D. Pedro I: el Poder Moderador, el Consejo de Estado y la transformación del Senado vitalicio en uno de carácter temporal. El objetivo final era hacer del Imperio una monarquía federal. Los liberales moderados, llamados chimangos, preferian la reforma del Poder Moderador a su extinción. Los conservadores o caramurus eran

4 Cf. João Camilo de Oliveira Torres, A democracia coroada. Teoria politica do Império do Brasil, 2 ed, Vozes Limitada, Rio de Janeiro, 1964, p. 44; Jorge Miranda, Manual de direito constitucional. Tomo I, 6 ed, Coimbra Editora, Coimbra, 2010, pp.212-214.

${ }^{5}$ Cf. Luiz Fernando Fauth, "A formação dos partidos politicos brasileiros no Império e na Primeira República”, Análise, vol.7, $\mathrm{n}^{\circ} .2,1996, \mathrm{pp} .93-94$.

6 Cf. Thiago Fernandes Boverio, Fidelidade partidária e a eficácia normativa da resolução do Tribunal Superior Eleitoral que disciplina o procedimento de perda do cargo eletivo por desfiliação partidária sem justa causa, Trabalho de Conclusão (curso de Especialização em Direito Legislativo), Universidade do Legislativo Brasileiro, Brasilia, 2008, p. 10. 
partidarios de mantener la estructura funcional tal y como fue diseñada originalmente en la Constitución de 1824 y de la vuelta del propio D. Pedro I.

En este contexto de transformación y progreso frente a conservadurismo e involución van surgiendo las primeras organizaciones partidarias bajo la forma de Sociedades como la Federal, la Sociedad Defensora de la Libertad y la Independencia Nacional y la Sociedad Restauradora que agrupan a los respectivos credos ideológicos anteriormente descritos. Su forma se pareció más a la propia de facciones, grupos de notables o comités meramente electorales.

Los "partidos de cuadros" tenían por preocupación central la satisfacción de los intereses propios de las élites que los sustentaban: los grandes propietarios rurales del Partido Conservador y los profesionales liberales del Partido Liberal. Los latifundistas y las élites ilustradas no pretendieron configurar un cuadro institucional estable y profundizar en la organización interna e ideológica de los partidos. La organización politica era propiedad de las élites, concretamente de aquéllas que ocupaban la Assembléia y el Senado en dos composiciones eminentemente facciosas de designación conservadora y liberal ${ }^{7}$.

Los dos grandes "partidos" de la época imperial representaron las dos ideologias dominantes: el Partido Liberal y el Partido Conservador ${ }^{8}$. La función principal de uno y otro era, una vez alcanzado el poder por turnos, el control del gabinete imperial ${ }^{9}$. Este duopolio se vería alterado por la aparición en 1862 del Partido progresista, unión de liberales y conservadores moderados, y del Partido Republicano en 1970. En esta agremiación partidaria se depositaron, frustradamente, las esperanzas de un cambio en el reparto del poder. Su línea de acción consistía en lograr la caída del Emperador sin alterar las divisiones de clases existentes en la época.

La figura dominante no fue el partido como organización dotada de coherencia ideológica, organizativa y programática. El elemento aglutinador del voto fue el poder fáctico de los caudillos politicos. La aristocracia agraria era dueña y señora del juego político. El gobierno simbolizaba, en primer lugar, el poder y las aspiraciones de la clase dominante: los señores de la tierra. La falta de coherencia programática e ideológica de la época se resumía en la máxima "Nada más conservador que un liberal en el poder, nada más liberal que un conservador en el poder"10.

Los "partidos" que se formaron en la etapa imperial no representaban en modo alguno los intereses de los diferentes sectores de la sociedad civil. Se asemejaban en mayor medida a un producto surgido de un Estado compuesto y

${ }^{7} \mathrm{Cf}$. Carlos Bastide Horbach, "O parlamentarismo no Império do Brasil (II). Representação e democracia”, Revista de Informação Legislativa, nº 174, 2007, p.214.

8 Cf. Orlando Soares, "Origens das Organizações Partidárias e os Partidos Politicos Brasileiros", Revista de Informação Legislativa, $n^{\circ}$. 103, 1.989, p.169.

9 Cf. Afonso Arinos de Melo Franco, História e teoria dos partidos politicos no Brasil, 3 ed, Alfa Omega, São Paulo, 1980, pp.23 y ss; Palhares Moreira Reis, "Os Partidos Politicos e a Experiência Brasileira", Revista de Informação Legislativa, n 114, 1992, p.96.

${ }^{10} \mathrm{Cf}$. Varimeh Chacón, História dos partidos brasileiros: discurso e práxis dos seus programas, Universidade de Brasília, Brasília, 1981, pp.24 y ss; Vânia Siciliano Aieta, Partidos Politicos. Estudos em homenagem ao prof. Siqueira Castro. Tomo IV, Lúmen Juris, Rio de Janeiro, 2006, pp. 32 y ss. 
dirigido por diferentes oligarquías locales bajo la tutela constante del Emperador. La participación política era un privilegio de clase en manos de los propietarios o de aquellos ciudadanos suficientemente ilustrados. Se iniciaba una cultura política basada en el dominio de las oligarquías regionales y el culto a los personalismos por encima de la participación política del conjunto de la ciudadanía. Factores que, como veremos, dificultarian la formación de un sistema partidario que contribuyese al desarrollo de prácticas reconocidamente democráticas.

\subsection{La República Vieja: los partidos son constitucionalmente ignorados.}

La llegada de la Primera República en 1889, conocida popularmente como "República Vieja", supuso la total reestructuración de la organización política brasileña. El centralismo característico de la etapa imperial dio paso a un modelo de organización territorial y politica caracterizada por el federalismo, el presidencialismo y la ampliación formal del régimen representativo a colectivos sociales hasta entonces apartados de la vida política. La nueva Carta Constitucional haría de los estados más poderosos económicamente - São Paulo y Minas Gerais- elementos centrales de la articulación de la vida política brasileña.

La inauguración del periodo republicano acabó con unos partidos fuertemente desprestigiados durante la etapa imperial. La herencia recibida los convertia en estructuras ineficientes para la satisfacción de los nuevos intereses federales. La nota dominante sería nuevamente la fragilidad organizativa y falta de liderazgo político en la creación de las instituciones republicanas. Esta realidad contribuyó a que la instauración de la República fuese en buena medida consecuencia de la acción directa de un Ejército articulado en una especie de partido sui generis. El recién instaurado gobierno provisional de la República se encontró con un problema de ocupación de las múltiples instancias estatales recién creadas, objeto de luchas entre las diversas facciones politicas sobrevivientes al periodo anterior. Las elites dominantes seguian considerados a los partidos como un obstáculo para la idea de "democracia" que tenían en mente: patrimonialista y excluyente de las clases populares.

La única excepción a este panorama de confusión fue la facción republicana que en 1893 se articuló en Partido Republicano. Esta agrupación ejercerá el control sobre la maquinaria administrativa federal y estatal mediante coaliciones políticas con las diversas oligarquias locales y bajo la atenta vigilancia de un Ejército que desde entonces se arrogaría para sí la condición de árbitro supremo de la vida política brasileña.

La Republica Vieja no contó con la existencia de partidos propiamente dichos ante la inexistencia de organizaciones de carácter nacional. La participación de los grupos políticos, numerosa, se organizaba mediante diferentes grupos estatales y unos electores agrupados alrededor de los lideres locales. No por casualidad las primeras organizaciones partidarias surgidas en la República responderían a esta nueva visión de predominio de las organizaciones regionales sobre las nacionales, como así indica la fundación en 1890 del Partido Republicano Histórico do Rio Grande do Sul y el Partido Operário de São Paulo. 
La dinámica electoral estaba contaminada por el indisimulado fraude promovido desde la maquinaria estatal. Los caudillos del partido elegian a los candidatos y los convertian en electos a través de procesos electorales claramente fraudulentos conocidos popularmente como elecciones "a punta de pluma", en las cuales se falseaban las actas y/o la elección "de puñetazo", que garantizaba a través de la violencia el voto exclusivo de los afines a una determinada sección electoral. Completaba este peculiar cuadro el denominado "tercer escrutinio", mecanismo de reconocimiento a nivel del Congreso de aquellos que participaban junto al grupo dominante ${ }^{11}$.

La situación de ignorancia constitucional y legal hacia los partidos iniciada en la última etapa del Imperio se reprodujo en la etapa republicana. Ni la Constitución de 1891 ni la legislación infraconstitucional les dedicaron un solo artículo. El derecho de asociación del art. $72, \S 8^{\circ}$ no los contempló directamente. Aquellos seguían siendo considerados por la doctrina y los medios de comunicación facciones aglutinadoras de intereses de clase. Fue el Código Civil de 1.916 quien los reconoció por primera vez como personas jurídicas de Derecho Privado. Por otra parte, la introducción de la democracia representativa en el texto constitucional - art. 16, § 2 y 28 - no llevó aparejado su reconocimiento como articuladores necesarios de la representación democrática.

En materia de sufragio, la Constitución Republicana de 1891 implantó un modelo sui generis de sufragio universal en el que la única mejora reseñable fue la eliminación de la renta como condición de elector. Los menores de 21 años, las mujeres y los analfabetos quedaban excluidos del proceso electoral. Estas condiciones continuaban haciendo de las elecciones un mecanismo fraudulento de perpetuación de las élites regionales. De los 11 procesos electorales celebrados durante la primera República tan solo el del año 1930 llegase a alcanzar la cifra del $5 \%{ }^{12}$.

En el ámbito federal iban surgiendo nuevos partidos politicos con diferente grado de penetración en el complejo entramado territorial de la República. En 1902 se fundó el Partido Socialista. En 1910 fue el turno del Partido Republicano Conservador, resultado de su separación del Partido Republicano original. En 1913 surgió el Partido Republicano Liberal, que tuvo como miembro más destacado al senador Rui Barbosa, eterno candidato a la Presidencia de la República.

Sería el Partido Comunista do Brasil, fundado en 1922, la primera organización partidaria de carácter nacional basada en la concepción orgánica de partido y que contaría con una incipiente representación social de carácter antagónico a la propia de los grupos políticos dominantes. Su declarada defensa del sector obrero y su firme intención programática de transformar el orden social existente motivó su declaración de ilegalidad apenas tres meses más tarde de su fundación. Otra organización partidaria de expresión nacional de menor relevancia en el escenario político sería el Partido Democrático Nacional fundado en 1927.

${ }^{11}$ Cf. Palhares Moreira de Reis, "Os Partidos Politicos e a Experiência Brasileira", op.cit, p. 96

12 Cf. Maria D’Alva Gil Kinzo, "O quadro partidário e a constituinte", Revista de Ciência Política, v.1, nº.1, 1989, p. 99. 
La mentalidad de la Primera República puede definirse, de acuerdo con Arinos de Melo Franco, como esencialmente federal y antipartidaria en sentido nacional ${ }^{13}$. La prioridad del gobierno republicano fue la creación de organizaciones políticas regionales comprometidas con los intereses económicos de los productores de café, los coroneles y los grandes latifundistas. Este ambiente institucional dificultó sobremanera la formación de estructuras politicas nacionales dotadas de un programa político coherente y una ideología fácilmente reconocible.

La preferencia era nuevamente la defensa de intereses elitistas regionales aglutinados en la figura del caudillo político. Los partidos se estatalizaran con el objetivo de atender las demandas regionales de los grupos dominantes. Cada Estado miembro se cerró en sí mismo, preso de las respectivas familias $u$ oligarquías. El poder político se repartía fraudulentamente entre los dos principales vectores políticos y económicos: Minas Gerais y São Paulo. Sus partidos respectivos, el Partido Republicano Paulista y Republicano Mineiro establecieron la popularmente conocida "politica do café com leite". Este procedimiento se resumía en el apoyo del Gobierno central a la oligarquía victoriosa en el Estado correspondiente. De este modo, el juego de alianzas y apoyos reciprocos posibilitaba que el gobierno federal favoreciese al grupo que le apoyaba en el poder y destruyese a la oposición valiéndose de la estructura jurídica de que disponía.

No cuesta trabajo entender que la representatividad democrática no era en modo alguno una preocupación republicana ${ }^{14}$. Los escasos líderes con verdadera conciencia republicana no lograron organizar estructuras partidarias de carácter nacional debido a diversos factores como la inexistencia de cultura partidaria, la falta de contacto con las masas y, sobre todo, por la concentración de poderes que la Constitución otorgada al Jefe de Gobierno y que le permitía gobernar sin la necesidad de contar con el apoyo de aquéllos.

La organización política que cambiaría los designios de la Primera República fue la Aliança Liberal fundada en 1929. Su manifiesto fundacional denunciaba las prácticas fraudulentas ya comunes en los procesos electorales. Esta formación politica expresa mejor que cualquier otra la preeminencia de las organizaciones estatales sobre las de carácter nacional. Fruto más bien de la necesidad que de la afinidad ideológica y programática, estaba compuesta por las fuerzas representativas de Minas Gerais, Rio Grande do Sul y Paraiba do Norte. Su líder, Getúlio Vargas, concurriría a las elecciones presidenciales de marzo de 1930. Su derrota frente a Júlio Prestes, considerada como un nuevo caso de fraude electoral, precipitaría la caída de la República mediante la marcha de 1930. Se abría así la Era Vargas.

\subsection{Los partidos politicos en la Era Vargas.}

\subsubsection{Del Gobierno Provisional al Estado Nuevo (1930-1937).}

${ }^{13} \mathrm{Cf}$. Afonso Arinos de Melo Franco, História e teoria dos partidos politicos no Brasil, 3 ed, op.cit, p.53.

14 Cf. Alaor Barbosa, "Partidos politicos: aspectos do fenômeno", Revista de Informação Legislativa, $\mathrm{n}^{\circ} .103,1989, \mathrm{p} .220$. 
El Ejército, como se apuntó en el apartado anterior, se había constituido durante la Primera República en una suerte de árbitro de la vida política nacional. La caída del Imperio y la proclamación de la República se debió en buena medida a su intervención directa. El intervencionismo militar se produjo nuevamente ante el advenimiento de circunstancias politicas, económicas y sociales que hacian imposible el mantenimiento del status quo. La cúpula militar se encargó de deponer al Presidente electo de turno - Washington Luis - y entregar el poder al líder de la Aliança Nacional, Getulio Vargas. El golpe de Estado fue la reacción al fracaso de numerosas tentativas de conciliación de las clases dominantes con el presidente y el fruto del miedo a que las clases populares se adelantasen a las élites políticas. Nadie mejor que el líder político minero Antonio Carlos resumió el espíritu del momento con aquella clásica expresión de "hagamos la Revolución antes de que la haga el pueblo". La nueva burguesía urbana y nuevas oligarquías exigian entrar en el reparto del poder politico ${ }^{15}$.

El Gobierno Provisional de Vargas tuvo entre sus prioridades extinguir las agremiaciones heredadas de la Primera República. Ni las instituciones principalmente el Congreso - ni los partidos y las oligarquías estatales de Minas Geráis y São Paulo a las que éstos servian se interpondrian en su proyecto de poder caudillista. La consigna era la vuelta al centralismo autoritario, la sumisión de las oligarquías regionales y la cooptación o eliminación directa de aquellos partidos que supusiesen cualquier obstáculo a su aspiración de control férreo de la esfera estatal.

En febrero de 1932 fue promulgado el primer Código Eleitoral Brasileiro (en adelante, $\mathrm{CEb}$ ). Una de sus grandes novedades fue el reconocimiento por vez primera de la existencia jurídica de los partidos y las bases de su organización (arts. 99 y 100). Los partidos políticos podian ser permanentes o provisionales. Permanentes eran aquellos que hubiesen adquirido personalidad jurídica de Derecho Privado de acuerdo al art. 18 del Código Civil de 1916. Provisionales serian aquellos sin personalidad jurídica pero con el apoyo de 500 electores. En materia de sufragio, el $\mathrm{CEb}$ introdujo el voto secreto, universal y directo, la representación proporcional y por primera vez reconoció el sufragio femenino. Creó igualmente la Justiça Eleitoral y prohibió el voto a mendigos y analfabetos. Este último punto es suficientemente ilustrativo del carácter excluyente de la participación política orquestada por las oligarquias dominantes. Un factor que acentuaba la debilidad del sistema de partidos.

El enfrentamiento entre Gobierno Central y Estados iba endureciéndose progresivamente hasta el punto de que entre los meses de junio y octubre de 1932 explotó en São Paulo el denominado levante Constitucionalista. Este enfrentamiento entre la facción central y estatal del gobierno reforzó la vocación estatal de los partidos politicos. La derrota de los insurgentes paulistas, por paradójico que pueda parecer, aceleró el fin del Gobierno Provisorio de Vargas y la convocatoria de la Asamblea Constituyente de la cual nacería la Constitución de 1934. El resultado fue nuevamente el querido por las viejas oligarquías y los partidos estatales que, bajo nuevos eslóganes pretendidamente populares, no

15 En este sentido, cf. Reginaldo de Souza Vieira, Partidos Politicos Brasileiros. Das origens ao Princípio da Autonomia Político-Partidária, Unesc, Criciúma, 2010, p. 77. 
hicieron otra cosa que atender los intereses de los sectores más conservadores de la sociedad brasileña.

La Constitución de 1934 reflejó el estado de descrédito doctrinal que seguía afectando a unos partidos considerados poco más que la correa de transmisión de los intereses propios de los gobernadores estatales ${ }^{16}$. No hubo rastro alguno de querer mudar la fisonomía eminentemente estatal y oligárquica de los partidos en favor de nuevas organizaciones de carácter nacional representativas de los diferentes intereses sociales. El art. 26, que decretaba la capacidad del Congreso para definir su reglamento interno, exigia que en todas las Comisiones se respetase en la medida de lo posible la representación proporcional de las diferentes corrientes de opinión. Los partidos no eran presentados como entidades definidas. Simplemente eran considerados meras corrientes de opinión jurídicamente informes. El otro dispositivo constitucional que los mencionaba, el artículo 170, § 9, tenía por objeto punir la conducta de aquél funcionario que usase de su posición para favorecer a los partidos. De esta exigua regulación constitucional puede deducirse la decidida connivencia de legislador y élites politicas en restringir su vida funcional a la mínima expresión jurídica.

En 1935 se publicó el segundo $\mathrm{CEb}$, la Lei 48, que mantuvo en gran parte las previsiones adoptadas por su precedente de 1932. Los artículos 166 y 167 seguian considerando partidos políticos permanentes a aquéllos que se registrasen de acuerdo a los términos establecidos en el artículo 18 del Código Civil. Igualmente, redujo el cupo de 500 electores del Código del 32 a 200 para los partidos provisionales. Su mayor novedad fue la introducción de las candidaturas independientes en su artículo 48. Una muestra más de la falta de interés del legislador en articular partidos de vocación nacional.

Los datos aquí expuestos permiten afirmar que el periodo 1930-1937 se destacó por exacerbar la cultura antipartidista propias del Imperio y la República Vieja. Los partidos seguian siendo considerados, con mayor fuerza si cabe, elementos disgregadores y facciosos únicamente interesados en ampliar los intereses de las clases dominantes y radicalizar la lucha de clases ${ }^{17}$. E1 reconocimiento jurídico de los partidos en el $\mathrm{CEb}$ no se acompañó de una adecuada libertad de actuación en el marco de las instituciones legislativas. Paralelamente, la introducción de las candidaturas independientes (art. 88) posibilitó la persistencia de grupos económico-políticos únicamente interesados en el mantenimiento de sus privilegios de clase. La organización y consolidación de partidos nacionales verdaderamente representativos tendría que esperar otros tiempos.

Este estado de cosas permite afirmar que no puede hablarse de la existencia de partidos politicos modernos durante la primera etapa de gobierno de Vargas. Los grupos oligárquicos de la Primera República, que controlaban con puño de hierro los partidos estatales, se limitaron simplemente a cambiar sus eslóganes. $\mathrm{Ni}$ rastro de sustituir su vocación de clase por la representación de intereses nacionales. A ello hay que sumar una cierta incapacidad de las élites políticas

16 En este sentido, véase, entre otros, Paim Vieira, Organização Profissional e Representação de Classes, São Paulo, Empresa Gráfica da Revista dos Tribunais, 1933, pp. 195 y 198.

17 Cf. Maria do Carmo Campello de Souza, Estado e Partidos Políticos no Brasil (1930 a 1964), 3 ed, São Paulo, Alfa-Omega, 1990, p. 65. 
para organizarse como partido, consecuencia de un instinto personalista y clientelar a medio camino entre el impulso atávico y la herencia histórica ${ }^{18}$.

Este escenario de aversión a los partidos, sumado a la ilegalización del Partido Comunista do Brasil que aglutinaba el movimiento operario y popular, a la connivencia de las viejas oligárquicas con el gobierno central y a la lealtad del Ejército al propio Vargas, fueron obstáculos insalvables para la aparición y consolidación de un cuadro partidario mínimamente reconocible. El resultado no podía ser otro - de acuerdo a los deseos del gobierno central, ejército y grupos conservadores - que la instauración de un régimen dictatorial que supuso el golpe de gracia al orden constitucional surgido de la Constitución de 1934 y, obviamente, al conjunto de organizaciones partidistas. Nacía así el Estado Nuevo.

\subsubsection{El Estado Nuevo (1937-1945)}

En Noviembre de 1937 el Gobierno presidido por Getúlio Vargas dio el golpe de Estado que puso fin al gobierno provisional y provocó el advenimiento del Estado Nuevo. El Congreso fue cerrado y los partidos políticos fueron declarados ilegales. Las únicas entidades sindicales y populares subsistentes serian aquellas que estuviesen directamente sobre control del Estado. Este periodo contaria con un nuevo texto constitucional, el de 1937, conocido popularmente como la "Constitución Polaca". Su espíritu estaba notoriamente inspirado en los regimenes autoritarios existentes en aquella época en Europa y, como su propio pseudónimo indica, en el régimen polaco.

El Preámbulo de la Constitución otorgada por el dictador Vargas dejaba bien claro la intención del mismo respecto a los partidos. Según el mismo, no cabía la posibilidad de convivir en un régimen en el cual existiesen los partidos políticos. El texto constitucional imposibilitó por acción y omisión el surgimiento y consolidación de las organizaciones partidarias. Sobre todo de aquellas que fuesen contrarias al plan de dirección politica del recién inaugurado régimen dictatorial. El órgano partido no recibió mención alguna en el texto constitucional. El modelo de Estado que se implantaría sería de corte corporativo. El Parlamento fue eliminado en todos sus niveles y el derecho de asociación se mantuvo "de acuerdo a la ley y las buenas costumbres".

El tiro de gracia a los partidos fue obra del Decreto Lei $\mathrm{n}^{\circ} 37$, de 2 de diciembre. Quedaban extinguidos oficialmente todos los partidos politicos registrados en los Tribunales Superior y Regionales de la Justicia Electoral. El artículo $3^{\circ}$ establecía que los partidos estarian prohibidos en cualquiera de sus formas en tanto no se produjese la promulgación de la ley electoral. Una circunstancia que únicamente se produciría en los estertores del Estado Nuevo motivada por la irresistible presión internacional y en menor medida nacional. La única cédula política admitida fue la Legião Cívica Brasileira creada en 1938. Fue esta asociación un embrión del malogrado Partido Único característico de los regimenes nazi-fascistas del momento. Los militares se encargaron de evitar su consolidación ante la posibilidad de perder parte de su ascendencia sobre el gobierno.

18 Cf. Maria do Carmo Campello de Souza, Estado e Partidos Politicos no Brasil (1930 a 1964), 3 ed, op. cit, p. 65. 
El Estado Nuevo, si bien no consiguió establecer orgánicamente la teoría del partido único propia de los regimenes autoritarios, no se olvidó de suprimir todos los restantes ${ }^{19}$. Tan solo el PCB, ya ilegalizado, consiguió sobrevivir en la clandestinidad. El fin de la Segunda Guerra Mundial posibilitó la aparición de una corriente de opinión opositora que cristalizó en el Manifesto dos Mineiros, de octubre del 43, en el que se pedía el fin del régimen dictatorial y su sustitución por un régimen auténticamente representativo. El continuo fortalecimiento de la opinión pública nacional e internacional en favor de la democracia aceleró diversas reformas aperturistas lideradas por el propio Getúlio, que no descartaba conducir la transición y mantenerse en el gobierno una vez acabada la fase reformista. Con lo que no parecía contar Getúlio era con la oposición frontal del Ejército, quien una vez más se erigió en juez de la vida política brasileña y forzó su renuncia.

\subsection{Los partidos durante el periodo democrático 1945-1964.}

La democracia no conseguía arraigar en Brasil. A cada tentativa modernizadora le seguía una reacción autoritaria en defensa de los intereses de clase dominantes. La Era Vargas no estimuló en modo alguno la formación de un sistema partidario estable y cohesionado. Las instituciones corporativas y estatales, así como los organismos gubernamentales, tendian a aislar o minorar la influencia de los partidos en el sistema político. La prioridad no era otra que salvaguardar de la acción partidaria las decisiones estratégicas del gobierno central $^{20}$. De otra parte, la permanencia de las élites partidarias en los cuadros de poder durante y después del golpe no iba a facilitar la necesaria reconversión de los partidos en organizaciones dotadas de coherencia ideológica y carácter nacional. La Constitución de 1946, obra nuevamente de la élite política, dejaría incólume los cimientos institucionales del Estado Nuevo : el sistema de interventores, el movimiento sindical corporativista, un aparato burocrático estatal que conservaba amplias parcelas de decisión y la subsistencia de la ideología autoritaria del Estado ${ }^{21}$.

El Decreto Lei n. 7.586/ 1945 puede considerarse un marco jurídico innovador en materia de organización y funcionamiento partidaria. El art. 109 impuso el requisito de contar con un apoyo minimo de diez mil electores repartidos entre 5 estados con apoyo, al menos, de 500 electores en cada uno de ellos. El art. 110, § 1 lo concebía por vez primera como entidad con actuación obligatoria en el ámbito nacional. La naturaleza jurídica continuaba siendo privada y su inscripción había de darse según lo previsto por el art. 18 del Código Civil.

El Decreto-lei 9.258/46 concretó los requisitos precisos para la constitución de un partido político: un claro apoyo electoral - 50.000 electores - y clara vocación nacional - presencia orgánica en 5 estados y un apoyo mínimo de 1.000

19 Cf. Afonso Arinos de Melo Franco, História e teoria dos partidos políticos no Brasil, 3 ed, op.cit, p.77.

20 Cf. Vânia Siciliano Aieta, Partidos Politicos. Estudos em homenagem ao prof. Siqueira Castro. Tomo IV, op.cit, p.83.

${ }^{21}$ Cf. Maria do Carmo Campello de Souza, Estado e Partidos Politicos no Brasil (1930-1964), 3 ed, op. cit, p. 105. 
electores en cada uno de ellos. La adquisición de la personalidad jurídica se haría en los términos del Código Civil.

La Constitución de 1946, obra de representantes elegidos de las leyendas partidarias, añadió poco al reconocimiento institucional de los partidos. La principal novedad, ya presente en el Decreto-Lei n. 7.586 de 1945, era su reconocimiento como organizaciones nacionales a las cuales se les garantizaba la representación proporcional en los términos de la ley (art. 134). El artículo 141, § 13 introducía el concepto de democracia militante al prohibir el registro y funcionamiento de aquellos partidos cuyo programa o acción politica contrariase el régimen democrático, el pluralismo partidario y los derechos fundamentales del Hombre. Otras disposiciones de marcado tono antipartidista eran la posibilidad de que en las elecciones mayoritarias un mismo candidato pudiese inscribirse en más de una leyenda partidaria y concurrir a cuantos cargos representativos se disputasen en los diversos Estados de la federación. El tono general del texto constitucional era de continuismo en la tónica de restricción de la actividad político-partidaria de los años 30.

El Tribunal Superior Eleitoral concedió registro provisional a 32 organizaciones partidarias. La dureza de los requisitos exigidos para su inscripción definitiva hizo que entre 1947-1952 un total de 16 organizaciones vieran su registro cancelado. Otros 3 se fundieron entre sí. En marzo de 1964, fecha del golpe, habia un total de 13 partidos con registro definitivo $y$ funcionamiento legal en todo el país. A ellos debe añadirse un PCB que operaba en la clandestinidad desde $1947^{22}$.

La contradicción normativa era evidente. De una parte, se potenciaba por primera vez la figura de los partidos de carácter nacional al tiempo que se prohibian las candidaturas independientes. Los partidos iban a ser los únicos vehículos de canalización de la oferta electoral. Por otra parte, los requisitos exigidos desestimulaban la formación de nuevos organizaciones partidarias. Al mismo tiempo, la posibilidad de concurrir a diversos cargos representativos en diferentes Estados estimulaba la aparición de fuertes liderazgos individuales por lo general enfrentados a los partidos ${ }^{23}$.

Las dificultades legales establecidas buscaban impedir la proliferación de nuevos partidos estatales al estilo de la República Vieja. Por detrás de esta regulación se percibe claramente la intención de favorecer la subsistencia de los partidos provenientes del periodo anterior: el Partido Social Democrático (PSD) y el Partido Trabalhista Brasileiro (PTB). El otro grupo político dotado de cierta cohesión nacional y electoralmente representativo era la União Democrática Nacional (UDN). Este último vendría a ser el principal partido de oposición.

De forma análoga a periodos anteriores el PCB fue objeto de persecución institucional ante su creciente importancia electoral. La caza de brujas, si se admite la metáfora cinematográfica, se inició con la ilegalización del registro del partido. Por si no fuera suficiente, el propio Presidente Eurico Gaspar Dutra promovió la remoción de los mandatos de los parlamentarios pertenecientes a las

22 Cf. Rogério Schmitt, Partidos politicos no Brasil (1945-2000), Jorge Zahar, Rio de Janeiro, 2000, p. 13.

${ }^{23} \mathrm{Cf}$. Orides Mezzaroba, Introdução ao direito partidário brasileiro, Lúmen Iuris, Rio de Janeiro, 2003, p. 190 . 
siglas comunistas. La Lei $211 / 48$ confirmó tal medida. Un acto que reflejaba nítidamente el entendimiento que del concepto democracia tenían el resto de fuerzas politicas nacionales representadas en el Congresso Nacional. El PCB seguiría operando en la clandestinidad.

El sistema político del periodo 1945-1962 sufrió paulatinas variaciones motivadas por el esfuerzo de los partidos en adquirir una sólida estructura interna a nivel nacional. Era la única forma de superar las seculares desavenencias ideológicas entre los estados y la organización nacional, tan dañinas para la consolidación de la democracia. A pesar de sus imperfecciones entre las que destacan la prohibición del voto analfabeto y la restricción de la libertad ideológica de los partidos - el periodo comprendido entre 1945 y 1964 puede considerarse la primera experiencia democrática en la historia brasileña. En ningún momento anterior se combinaron dos factores elementales si se quiere hablar de sistema democrático sin caer en el ridiculo: el sufragio universal y las elecciones periódicas competitivas.

La fragilidad organizativa e ideológica de los partidos, utilizados mayoritariamente como meras máquinas electorales y plataformas de liderazgos personalísimos, favoreció la intervención militar que desembocó en la dictadura militar. Los partidos no lograron arraigar en el plano nacional ante su extrema dependencia del aparato del Estado, su escasa penetración social y su marcado carácter personalista, absolutamente descomprometidos con la elaboración de un programa dotado de coherencia y solidez ideológica en el plano nacional. Cuando fueron atacados por la corriente conservadora que solicitaba nuevamente la intervención militar y la instauración de un régimen dictatorial no pudieron presentar batalla alguna. El Ejército volvía a ejercer su papel de guardián de las instituciones politicas. Esta vez, implantando un régimen dictatorial que pondría fin al gobierno de João Goulart.

\subsection{E1 “bipartidismo" de la dictadura militar 1964-1978 y la apertura democrática.}

El periodo dictatorial se abrió con la edición del Ato Institucional 1. Este documento pretendia revestir de legitimidad de origen la "revolución victoriosa" de 1964. Se abría con ello la puerta a la constitución de un nuevo gobierno que, según se lee en el propio Ato, poseía la fuerza normativa inherente al Poder Constituyente. Los militares en el poder se invistieron de un poder arbitrario mediante el cual suspendieron los derechos políticos de un sinfin de ciudadanos incómodos para el régimen. Con ello se aseguraron cortocircuitar cualquier te

No fue esta la única medida de despolitización de la ciudadanía. El periodo dictatorial se destacó por la férrea limitación de la acción de los partidos. En julio de 1.965 se publicó la primera Lei orgánica dos Partidos Politicos. La amplitud de causas por las cuales las organizaciones ya existentes perderían su registro es buena prueba de ello. El artículo 47, I, exigía en el plazo de un año tras el registro del partido acreditar la formación de cuadros directivos en al menos once estados de la Federación. El art. 47, II, imponía la pérdida de registro a aquéllos que no obtuviesen doce diputados federales elegidos por un mínimo de siete Estados. El art. 47, III hacía lo propio con los que no hubiesen obtenido en elecciones generales para la Câmara Federal un minimo del 3\% del electorado nacional distribuido en once o más Estados. El art. 50, por su parte, permitía que el 
diputado mantuviese el mandato en caso de cancelación del registro del Partido si demostraba su oposición frontal a la orientación partidaria motivadora de la cancelación de Registro - salvo en los supuestos de contravención del régimen democrático, el pluralismo partidario o los Derechos Humanos -. El espíritu de la norma distaba mucho de favorecer la creación y consolidación de nuevas estructuras partidarias ${ }^{24}$. Tan solo 5 de los partidos existentes lograron mantener sus registros.

Solo unos meses más tarde el gobierno de Castelo Branco impuso la supresión de todos los partidos políticos a través del Ato Institucional $\mathrm{n}^{\circ} 2$ (art. 18). Fue la reacción a la derrota de las fuerzas del gobierno en los estados de Guanabara y Minas Gerais. Se enterraba de esta forma el sistema de partidos creado durante el anterior periodo democrático. La organización del nuevo marco partidario se haría depender de la recién editada Lei Orgánica dos Partidos Políticos de 1.965 (art. 18, parágrafo único). El 20 de noviembre del mismo año el gobierno impuso el sistema bipartidista a través del Ato Complementar $\mathrm{n}^{\circ} 4$. La Aliança Renovadora Nacional (ARENA) seria el soporte parlamentario del gobierno e incorporaría en sus cuadros a la gran mayoría de las élites que articularon el golpe. El Movimento Democrático Brasileiro (MDB) haría el papel de "oposición consentida" al régimen dictatorial. La polarización entre partido del gobiernopartido de oposición inducida por los gobernantes dificultó la aparición de un tercer partido que ocupase el centro del tablero político y motivó la despolitización de amplios sectores de la sociedad que no se sentian representados por las opciones existentes ${ }^{25}$.

La Constitución de 1967 buscó imposibilitar el surgimiento de un tercer partido en liza que pudiese contravenir la apariencia democrática del sistema bipartidista. El art. 149, VII, preveía que el funcionamiento del partido debería atender un quórum del 10\% del electorado que hubiese votado en la anterior elección general para la Câmara dos Deputados, distribuidos en dos tercios de los Estados y con el mínimo del $7 \%$ de los sufragios válidamente emitidos en cada uno de ellos. Todo ello además del apoyo expreso del 10\% de diputados federales distribuidos en un mínimo de $1 / 3$ de los Estados y el 10\% de los senadores.

Entre la Constitución del 67 y del 69 se editó el Ato Institucional 5 y el Decreto de Segurança Nacional. Uno y otro fueron resultado directo de las protestas del partido de oposición y de entidades surgidas de la sociedad civil. Entre los acontecimientos de protestas y huelgas se destacó la marcha de los 100.000 ocurrida en el 68 en Río de Janeiro. La lectura del Preámbulo del Decreto ofrece un cuadro que merece reproducir sus objetivos elementales. Decía el citado texto que el fundamento de la Revolución de 1964 tenía como objetivo asegurar la existencia de un orden democrático auténtico basado en la libertad, el respeto a la dignidad humana y el combate a la subversión y las ideologías contrarias a las tradiciones de nuestro pueblo. No requiere gran esfuerzo intelectual afirmar que se trataba de un ejercicio de voluntarismo político rayano en lo esperpéntico. 29.

${ }^{24}$ Cf. Rogério Schmitt, Partidos politicos no Brasil (1945-2000), Zahar, Rio de Janeiro, 2000, p.

25 Cf. Teresa M M Frota Haguette, "Cidadania: o Direito à Oposição e o Sistema de Partidos", Revista Brasileira de Estudos Políticos, nº.78-79, 1994, p. 78. 
La Constitución de 1969 maquilló en parte la contundencia de la regulación del 67, aunque sin efectos notorios en la modificación del sistema bipartidista. Moderó la desproporción de la clausula electoral reduciéndola a un $5 \%$ del electorado nacional total, distribuidos en un minimo de 7 Estados y con una votación mínima del $7 \%$ en cada uno de ellos. Eliminó igualmente el requisito de apoyo expreso de senadores y diputados federales. El artículo 152 introdujo una novedad: el instituto de la fidelidad partidaria. Los mandatarios públicos podian perder el mandato si desobedeciesen las directrices legitimamente establecidas por el partido. El objetivo no era, a pesar de las apariencias, fortalecer los partidos. Se trataba simplemente de controlar a aquellos diputados díscolos existentes en el partido del gobierno (ARENA).

La segunda Lei Orgánica de Partidos Politicos - Lei n. 5.682 de 21 de julio de 1971 - se limitó a reproducir los requisitos establecidos en sede constitucional. Este texto disciplinaba casi por completo su funcionamiento interno. No había cuasi margen de autonomía a excepción de la elección de la sigla partidaria y poco más. El Estado imponía su voluntad en materia de organización y funcionamiento interno de partidos. El control ideológico y organizativo dejaba poco o ningún espacio a la confección de programas políticos ideológicamente reconocibles y la consolidación de las estructuras partidarias en los diferentes ámbitos estatales.

El régimen dictatorial mostró una imaginación febril a la hora de crear e innovar soluciones electorales que pudiesen paliar las derrotas que la sociedad civil iba imponiéndoles en las urnas. En 1968 creó las sub-leyendas partidarias con el objeto de acomodar dentro del partido ARENA a las diferentes facciones existentes. La Lei 6.339, de julio de 1976, conocida como Lei Falção, prohibía la crítica al gobierno y la divulgación de la ideología y programas partidarios en los programas electorales. En 1977 el gobierno de Geisel promulgó el llamado Pacote de Abril que incluía el cierre temporal del Congresso Nacional, la ampliación de las sub-leyendas a las elecciones al Senado Federal y, no menos llamativa, la creación de los senadores biónicos. Su elección se realizaba de forma indirecta por Colegios Electorales estatales controlados en su mayoría por el partido del gobierno. De esta forma el Ejecutivo se garantizaba el control de buena parte de la cámara Alta.

La Enmienda Constitucional 11, de octubre de 1978, vino a alterar las reglas de creación y subsistencia de los partidos. Su funcionamiento se hacia depender del cumplimiento de un requisito alternativo: o contaba con el $10 \%$ de los miembros de la Câmara dos Deputados o el Senado Federal o bien cumplía con las siguiente clausula de barrera electoral: haber alcanzado el $5 \%$ de los votos en las elecciones a la Câmara dos Deputados, representando 9 estados de la federación y alcanzando, al menos, el 3\% de los votos en cada uno de ellos. Paralelamente, se admitía el abandono del diputado del partido para la creación de nuevas siglas sin que perdiese el mandato electivo. El objetivo de estas medidas respondía al intento de fragmentar el frente de oposición liderado por el MDB para posibilitar al gobierno el control hegemónico del proceso sucesorio ${ }^{26}$. $\mathrm{Si}$ la transición a la democracia era cuestión de tiempo, las élites querían

26 Cf. Reginaldo de Souza Vieira, Partidos Politicos Brasileiros, Das Origens ao princípio de autonomia partidária, op.cit, p. 96. 
garantizarse para sí una posición privilegiada en la creación del nuevo marco constitucional.

La derogación del Ato Institucional 5 y la Lei de Anistia supusieron la rehabilitación politica de los perseguidos por el régimen militar. Volvian aquellos líderes - entre los que cabe destacar a Lionel Brizola y Luiz Carlos Prestes condenados al ostracismo. Su vuelta suponía la articulación de nuevos partidos a través de los cuales canalizar las reivindicaciones de sus principales exponentes. El pluripartidismo iba tomando forma en su dimensión social.

El golpe de gracia al bipartidismo ficticio del periodo dictatorial fue otorgado por la Lei 6.767, de 20 de noviembre de 1979, autoria de Figueiredo, el último de los presidentes militares de la dictadura. Varios artículos de la Lei Orgânica dos Partidos Politicos fueron derogados con el objetivo de facilitar jurídicamente la creación de un espacio político pluripartidista. Su consecuencia más destacada fue la extinción de la ARENA y MDB y la creación de seis partidos que vendrian a disputarse la conquista de un nuevo espacio político: el Partido Democrata Social (PSD), el Partido do Movimento Democrático Brasileiro (PMDB), el Partido Popular (PP), el Partido Trabalhista Brasileiro (PTB), el Partido Democrático Brasileiro (PDT) y el Partido dos Trabalhadores (PT). Tan solo este último significaba una ruptura con la concepción de partido como entidad al servicio de los intereses de sus mandatarios principales. Se trataba del primer partido político orgánico caracterizado por la amplia participación de movimientos sociales y sindicales ${ }^{27}$.

Las elecciones de 1982 fueron los primeros comicios en un ambiente de pluripartidismo y amplia participación popular. 45 millones de personas fueron llamadas a ejercer el derecho de sufragio en el que ya se configuraría como el mayor Cuerpo Electoral de América Latina. Sin solución de continuidad nació el movimiento Eleições Diretas já en 1983 liderado por los habilidosos opositores Ulysses Guimarães y Theotônio Vilela. Oposición y sociedad clamaban por el retorno sin ambages de elecciones auténticamente democráticas. Para sorpresa y decepción de la ciudadanía la propuesta fue derrotada por un estrecho margen de 22 votos.

El año de 1985 trajo consigo una reforma del derecho de sufragio improrrogable para la consolidación de un régimen democrático: la inclusión del analfabeto como elector. El Estado se resarcía parcialmente de un histórico de marginación política de las clases más desfavorecidas. Por otra parte, el PCB y el $P C$ do $B$ fueron legalizados. La vuelta a la arena politica de las fuerzas comunistas significaba la consolidación de un escenario de pluralismo político más acorde a la redemocratización que se produciría con la entrada en vigor de la actual CF 1988.

El marco de continuo intervencionismo estatal que recorre la historia de los partidos influyó notablemente en la regulación constitucional que la CF 1988 hizo de los Partidos Politicos. La prioridad del constituyente no fue otra que garantizar por primera vez amplia libertad organizativa y de funcionamiento interno. El eje cartesiano de las relaciones Estado-partidos sería por vez primera el principio de libertad y autonomía de éstos últimos. No sin razón se tiene por admitido que la CF 1988 es, con mucho, el texto más liberal de la historia constitucional en

27 Cf. Teresa $\mathrm{M}^{a}$ Frota Haguette, "Cidadania: o Direito à Oposição e o Sistema de Partidos", op.cit, p. 83. 
materia de partidos. Se iniciaba una nueva etapa en la que los partidos, esta vez, asumirian un rol acorde a su importancia en el sistema democrático.

\section{A MODO DE CONCLUSIÓN.}

El reconocimiento legal y constitucional de los partidos en el ordenamiento jurídico brasileño puede definirse como un camino largo, tortuoso y lleno de altibajos. El siglo XIX se caracterizó por una actitud legal y doctrinal de rechazo a la formación de partidos políticos propiamente dichos. El sistema político brasileño se organizó alrededor de un bipartidismo de corte inequivocamente conservador y elitista. El mantenimiento del sufragio censitario y la inexistencia de elecciones libres y competitivas completaban un escenario en el que resultaba del todo punto imposible la necesaria transformación de la dinámica de funcionamiento de los partidos. En un Estado marcadamente patrimonialista no habia espacio para otra ideología y otros partidos que no fuesen los propios de los señores de la tierra.

El siglo XX fue igualmente conflictivo. La inexistencia de un mínimo consenso sobre la utilidad y conveniencia de crear y consolidar legalmente un sistema de partidos que favoreciese la estabilidad democrática fue la nota dominante en los diversos periodos de la vida politica brasileña. La Primera República no trajo consigo las mudanzas que en materia de participación politica y partidos cabía esperar. Su objetivo no fue en modo alguno instituir el espíritu republicano de bien común, justicia social y participación política que lo define. Todo lo contrario. Se trataba de seguir manteniendo los privilegios de una élite política cimentada alrededor de la propiedad rural, los intereses de clase y la exclusión de amplios sectores de la población. El derecho de participación política y de asociación seguía siendo territorio acotado para las élites.

La Era Vargas tuvo entre sus propósitos principales imposibilitar la creación de un sistema de partidos representativo de los diferentes sectores sociales que iban surgiendo y demandando espacio político. Un objetivo completamente alcanzado durante el Estado Nuevo con la prohibición total de las organizaciones partidarias. El periodo 1945-1964 permitió la existencia de un marco minimamente representativo y electoralmente competitivo por vez primera. Con todo, los partidos seguian sin disfrutar de un grado de reconocimiento constitucional acorde al dado por otros países de la órbita occidental que si lograrian consolidar la democracia. Su debilidad organizativa facilitó la toma del poder nuevamente por las élites dominantes con la connivencia del Ejército, erigido una vez más en árbitro de la vida política nacional.

El periodo dictatorial vino a ahondar las heridas del sistema partidario. Los partidos del periodo anterior fueron prohibidos. Se creó un sistema pretendidamente bipartidista al servicio de los intereses del gobierno dictatorial. Las derrotas electorales del partido del régimen, la ARENA, se veían paliadas por la utilización fraudulenta e indisimulada de la maquinaria legal con el objetivo de recomponer el status quo. Tan solo a partir del 78, cuando era evidente la periclitación del régimen, se dio paso a determinadas reformas jurídicas que 
posibilitarian la formación de un sistema pluripartidista que seguía adoleciendo de debilidad ideológica, programática y organizativa. El personalismo típico de la historia política brasileña seguía imponiéndose a la concepción orgánica de partido.

El reconocimiento constitucional expreso de los partidos brasileños se verá profundamente modificado con la entrada en vigor de la CF 1988. Por primera vez los partidos disfrutarán de un estatus y protección jurídica que, no hay como negarlo, ha contribuido decisivamente a la consolidación institucional del gobierno democrático en Brasil. Ello no es óbice para señalar la subsistencia de algunas marcas históricas como la debilidad programática y organizativa y la preeminencia de los liderazgos individuales sobre el órgano partido. Este escenario ha motivado el que sociedad civil y determinadas organizaciones políticas minoritarias vengan exigiendo desde finales de los 90 una amplia reforma política que refuerce el sistema partidario brasileño como un todo y haga del partido el eje central de la representación política. Cómo y cuando se atenderá esa reivindicación es otra historia de incierto final.

Enviado el (Submission Date): 4/02/2015

Aceptado el (Acceptance date): 18/04/2015 